\title{
ILUSÃO DE ÓPTICA: USABILIDADE NO DESIGN DE AMBIENTES
}

Maria Clara Ribeiro Araújo

Universidade do Estado de Minas Gerais - UEMG

mclaractc@gmail.com

Mara Galupo de Paula Penna

Universidade do Estado de Minas Gerais - UEMG

maragpenna@gmail.com

Resumo: A ilusão de óptica se traduz como um efeito visual criado pelo cérebro que acaba por distorcer a percepção de quem a observa. Sua base é pautada em aspectos psicológicos, sensoriais e imagéticos e sua aplicação é cabível a diferentes meios e dimensões ópticas. Em paralelo, o design de ambientes prevê a abordagem e aplicação da sinestesia a soluções projetuais, ao passo que a ação de iludir pode tanto associar-se a um de nossos sentidos quanto correlacionar-se sinestesicamente. Este artigo tem por objetivo estudar como a ilusão de óptica pode atingir a interatividade fisiológica e interferir cognitivamente nos usuários de um espaço tridimensional.

Palavras-chave: Ambiente, design, ilusão de óptica, anamorfose.

Abstract: Optical illusion is defined as a visual effect created by the brain that distorts the perception of the viewer. Its concept has psychological, sensory and imagery aspects and it can be applied in different ways and optical dimensions. In parallel, interior design provides the approach and application of synesthesia to design solutions, while the action delude can either join one of our senses as to correlate through the synesthesia. This paper presents the study of how the optical illusion can reach the physiological interaction and cognitively interfere on users of a threedimensional environment.

Keywords: Environment, design, optical illusion, anamorphic 


\section{INTRODUÇÃO}

O ser humano é considerado um detector hipersensível de disparidades entre duas imagens. Estamos em constante processo de análise daquilo que nos cerca, realizado inconscientemente pelos agentes de nosso aparelho visual. Entretanto, há situações inusitadas em que a consciência vem à tona para o seguinte questionamento: Podemos confiar em nossos olhos?

As ilusões de óptica são conseguidas não porque nossos sentidos julguem mal, mas justamente porque estes não julgam. A intervenção do cérebro nas avaliações figurativas e de percepção vai muito além das sinapses efetuadas e comandos enviados às demais partes do corpo. Elas referem-se a uma inquietação interna, na qual duvidamos da veracidade formal do mundo o qual o conhecemos e de nossas próprias interpretações.

A neurociência estuda aspectos que resultam na coerência entre o ver e o sentir. O tempo de entendimento das ilusões pelo observador é regulado por alguns fatores em pré-disposição, como a bagagem visual e experimental do mesmo. A quantidade de exercícios lógicos executados pelo cérebro também traduz um coeficiente para as decodificações.

Na pesquisa e compreensão desta curiosa área da óptica, que pertence por sua vez a conceitos da física, um terceiro domínio se manifesta: a Psicologia da Percepção e Forma. Seus princípios e leis são os verdadeiros fundamentos na obtenção de efeitos ilusórios que, aplicados a um ambiente físico, potencializam as incógnitas anteriormente ópticas ao nível de nossos demais sentidos.

Padrões geométricos repetitivos, uso de espelhos, efeito luz e sombra produzindo sensação de elementos vazados, a profundidade do preto em contraste ao branco, listras verticais para "alongar" e horizontais para "alargar". Estes são apenas alguns dos diversos recursos empregados por profissionais do design na demanda por ampliação visual de espaços tanto residenciais quanto comerciais. Objetos de estudo da psicologia da cor e forma que são usualmente atrelados a conceitos projetuais.

As categorias conceituais da Gestalt fornecem subsídios para o procedimento criativo e auxiliam na leitura visual da forma. Dentre as 26 categorias mais empregadas na percepção, algumas se destacam no uso para concepção das ilusões de óptica, sendo elas: Complexidade (muitas unidades formais demandando maior tempo de leitura); Profusão (excesso de unidades formais gerando ornamentação à figura); Incoerência (incompatibilidade de estilo e forma entre os elementos); Exageração (expressão visual amplificada e extravagante); Redundância (repetição ou excesso de elementos semelhantes); Ambiguidade (intenciona diferentes interpretações); Fragmentação (decomposição de elementos em unidade que se relacionam); Difusão (sensação de diluição por figuras desfocadas); Distorção (força o realismo, dramatiza e causa efeitos intensos); Ruído visual (interferências ou distorções que perturbam a harmonia).

A tangibilidade da ilusão de óptica em um espaço tridimensional, no que se refere à conceituação projetual, abrange desde a simples ideia de um figurativo intrigante até a discussão sobre o âmbito e/ou nível de sensações a serem despertadas. Para tal visualização, se faz necessária devida pesquisa aos mecanismos adotados pelas ilusões, visto que a mente humana sofre de constante influência do meio externo. 


\section{DESENVOLVIMENTO}

O design, como área das ciências sociais aplicadas, interfere, sensorialmente, por meio da psicologia da percepção e forma. Já na etapa de execução projetual, todo este estudo pautado nas associações sensoriais, emocionais e experimentais, é materializado de modo a adicionar aspectos como, por exemplo, funcionalidade aos pré-existentes no processo de conceituação.

Compreender as divergências entre espaço bi e tridimensional, está muito além da aparente obviedade. Claramente de suma importância à concepção de um ambiente, este quesito permite um maior entendimento da interatividade espacial, podendo ser avaliado inclusive por meio de objetos com ausência de fundamentos da ilusão de óptica. Em duas dimensões, mente e imagem colaboram ciclicamente no processo de interpretação, atuando para a coerência entre o ver e o sentir. Já em terceira dimensão, um novo elemento chave é adicionado ao cenário: o corpo. Sua percepção passa a extravasar os limites intelectuais e o termo "sentir" ganha inaudito significado. Estando agora em um espaço o qual não controlamos, tem-se por experiência substancial, participar ativamente daquilo que antes se media apenas pela "inteligência visual".

O processo de classificação dos fundamentos relacionados à ilusão de óptica é suscetível à alteração provocada pelos constantes estudos referentes ao tema. Em uma geração de drásticas evoluções, seria plausível afirmar que novas descobertas resultam em acréscimo de bagagem intelectual e, consequentemente, novas interpretações.

Grande parte das obras avaliadas tem como ponto de partida o método por tentativa e erro. Estudos de cor e forma, encaixe de elementos e transposição de faces são por vezes efetuados e, concomitantemente aperfeiçoados, tendo como um dos elementos de averiguação a própria auto avaliação do criador. A categorização poderia resumir-se em ilusões Ambíguas, Escondidas, Paradoxais, Pós-efeito, Anáglifas, Estereogramas e Anamórficas.

São consideradas ambíguas as ilusões com mais de uma imagem em cena, embutidas harmônica e proporcionalmente de maneira que a compreensão total de ambas as formas só pode ser obtida uma por vez (Figura 1). Nesta categoria, os recursos aplicados tem caráter de segregação figura - fundo (um dos princípios da Gestalt).

Sem significado aparente em análise superficial, porém com a promessa de uma descoberta surpreendente após certo período de observação, as ilusões escondidas são concebidas pela conexão de figuras mistas, com ou sem relação temática (Figura 2). Geralmente contam histórias por meio da imagem e têm como elementos a camuflagem e o mimetismo.

De impossível identificação lógica, as ilusões paradoxais (Figura 3) confundem por artifícios imagéticos impedindo o observador de distinguir "começo e fim" da forma ou cenário. A executividade deste grupo em um ambiente requer cuidado na delimitação de suas dimensões.

As ilusões pós-efeito consistem na observação fixa por alguns instantes em um ponto pré-determinado da figura e, em seguida, o direcionamento do olhar para uma superfície preferencialmente clara. Esta ação permite, por alguns segundos, a visualização da imagem original. $O$ uso da coloração em negativo (cores opostas às da imagem original) é o fator que promove este efeito, aplicado em ambientes na escolha 
do verde para paredes de hospitais, por exemplo. $O$ verde tem por cor contrastante 0 vermelho, a mesma do sangue, e deste modo propicia-se maior conforto visual aos profissionais da saúde.

Anáglifas são imagens replicadas sucessivamente proporcionando sensação de movimento e ilusão quantitativa (Figura 4). O uso de escalas em proporção geométrica, quase sempre seguindo uma forma central, e cores contrastantes sobrepostas em degrade, são os métodos adotados para alcance deste efeito óptico. É uma ilusão comumente executada em softwares para que se mantenha o padrão de visualização da imagem, evitando assim, a perda do efeito visual impactante. Chega, entretanto, a causar vertigem a determinados observadores, por sua maioria, com predisposição a enxaquecas ou enjoos, apresentando-se como arriscada sua execução em larga escala.

O auto-estereograma (Figura 5), no qual se percebe a ilusão a olho nu e não com auxílio de algum aparelho (como em seus métodos iniciais), tem por intenção a diferenciação de planos e contraste da profundidade, que o diferencia da maioria das ilusões (que almejarem tridimensionalidade). Para a mecânica do estereograma, é necessária visualização próxima demais para um enfoque e convergência confortáveis. Em resumo, a utilização desta categoria, bem como sua construção, requer um nível de habilidade do indivíduo. Sua incorporação ao projeto tridimensional seria potencialmente inacessível, termologia indesejável ao design de ambientes, e requer um minucioso estudo prévio para sua execução.

Por fim, as ilusões anamórficas (Figura 6), relacionadas ao uso da perspectiva para eliminação da profundidade contemplada de um ponto de vista específico, promovem interação de caráter lúdico. Esta categoria foi desenvolvida visando aplicação em espaços tridimensionais e, logo, é a mais utilizada para tal.

\subsection{Revisão de Literatura}

O cérebro opera na coleta de informações e guia o comportamento de maneira conveniente, não importando se a consciência está envolvida na tomada de decisão. Uma ideia se torna consciente não isoladamente, mas assimilada a um complexo de outras ideias já presentes na consciência. Portanto, a velocidade que se pode reagir a uma pergunta depende do tipo de pensamento prévio que se tem.

\footnotetext{
Quando o mundo é previsto, não há necessidade da consciência porque o cérebro está fazendo bem o seu trabalho. Por exemplo, quando você aprende a andar de bicicleta, é preciso muita concentração consciente; depois de algum tempo, quando suas previsões sensoriais foram aperfeiçoadas, o ciclismo torna-se inconsciente. Pela longa experiência, seu cérebro sabe exatamente o que esperar enquanto você faz seus movimentos. Assim você não está consciente nem dos movimentos, nem das sensações, a não ser que alguma coisa mude. Quando novas situações levam à violação de suas expectativas normais, a consciência entra em cena e seu modelo interno é adaptado. (EAGLEMAN, 2012. p, 60).
}

Hoffman (2000) acredita que um cego de nascença poderia distinguir um cubo de uma esfera, mesmo nunca os tendo visto, caso retomasse a visão ou tivesse um transplante de córnea realizado com sucesso. Se já os pôde tatear anteriormente, ele associa que mudanças de caráter tátil representariam mudanças visuais como ângulos 
e arestas protuberantes em contraponto à superfícies lisas. A construção da imagem por descobertas sensoriais poderia ser analisada pela fisiologia de certos animais. A cobra, por exemplo, realiza o mapeamento do ambiente e de possíveis presas por meio de suas fossetas, que utiliza da temperatura para tal feito.

\footnotetext{
A percepção é o único ramo da psicologia que tem sido consistentemente orientado para a adaptação, considerando sua tarefa uma engenharia reversa. O sistema visual não está ali para nos entender com belos padrões e cores; ele foi arquitetado para proporcionar uma noção das verdadeiras formas e materiais encontrados no mundo. (PINKER, 1954. p, 111).
}

Pensar na física sem considerar a neurociência é uma forma errônea de analisar certas situações. A primeira influi no uso e posicionamento de elementos materiais, porém a segunda, diz respeito a outro quesito fundamental à criação das percepções visuais: a tomada de decisões do cérebro.

O que se ensina tradicionalmente sobre a percepção é que os dados do sensório são vertidos no cérebro, sobem pela hierarquia sensorial e fazem com que sejam vistos, ouvidos, cheirados, provados ou sentidos "percebidos". Mas um exame mais atento dos dados sugere que isto está incorreto. $O$ cérebro é com razão considerado um sistema principalmente fechado que dirige sua própria atividade gerada internamente. Já temos muitos exemplos deste tipo de atividade; respiração, digestão e locomoção são controladas por geradores de atividade autônomos em seu tronco encefálico e medula espinhal. (EAGLEMAN, 2012. p, 54).

\subsection{Pesquisa de campo}

Para maior entendimento do processo de criação e execução de fundamentos ilusórios, desenvolveram-se estudos manuais abordando princípios de cor, forma, textura e perspectiva. Dispôs-se de materiais primordialmente escolares, além de outros encontrados em estabelecimentos de artes e ofícios. Estes estudos resultaram em melhor avaliação sobre o desenvolvimento e execução das ilusões de óptica apresentadas nos mesmos, bem como métodos aplicáveis a outras ilusões.

$\mathrm{Na}$ sequencia de imagens apresentadas (Figura 7), o resultado pretendido foi pautado em criação paradoxal que partisse de uma figura geométrica simples e habitual ao cérebro. Paradoxo, também conhecido como algo impossível ou incoerente, provoca ao cérebro o questionamento relativo ao seu estado de funcionamento. A distorção de afirmações realizadas diariamente como o estado gravitacional; início e término de fluxos; níveis de profundidade e a ordem de planos visuais influem diretamente em inquietações mentais para se alcançar respostas no mínimo razoáveis.

As sinapses cerebrais associam uma imagem complexa a uma solução potencialmente complexa, o que, rotineiramente, impede que acreditemos em nossos olhos quando estes afirmam que os segredos estão na própria figura. A correlação destas teorias é empregada em ilusões consideradas paradoxais, tendo como métodos comumente empregados: a coloração em degrade; rotação de formas replicadas e respectiva ligação concêntrica; quebra de padrão em escala e continuidade; utilização de texturas que se mimetizam ao longo do processo e aplicação de elementos familiares ao aparelho de visão (como a própria silhueta humana, por exemplo). 
Qualquer forma, e profundidade da mesma, criada em duas dimensões pode ser executada, afinal, trata-se de um desenho à mão livre. O que nos faz desacreditar na viabilidade desta imagem é a imediata tridimensionalidade criada pela luz e sombra, quando na verdade, sabemos que seria uma forma impossível de materializarse. Basicamente convertemos o imagético em ambas as dimensões antes de avaliarmos sua veracidade, ou ausência desta.

A perspectiva é um recurso secular amplamente utilizado em diversos meios artísticos como arquitetura, design e artes plásticas. Sua atratividade está na factível representação da forma assim como nossos olhos a veem, onde as linhas horizontais, paralelas em termos lógicos e reais, afunilam-se visualmente criando certa distorção decifrável ao cérebro. A descoberta desta aplicação permitiu que as representações se tornassem progressivamente mais realistas e envolventes perante os indivíduos, o que justifica ser atualmente um conhecimento indispensável às áreas da óptica e das artes.

A imagem apresentada (Figura 8) é resultado de um estudo manual efetuado a fim de se desenvolver uma ilusão com foco na perspectiva de seus componentes gráficos. A textura visual, aliada à distorção da forma, potencializa o efeito óptico criado e contrapõem o diálogo dos principais participantes neste processo: a visão dos olhos e a visão do cérebro. Para execução do desenho, utilizou-se: Criação de elipses irregulares e descentralizadas, porém, com seguimento em progressão geométrica; Divisão destas formas por curvas de espessura aproximada, com redução a cada elipse menor; Coloração dos fragmentos de alternado e, por fim, preenchimento em cor sólida rente ao menor ângulo com efeito em degrade a medida que o lápis percorre o papel. A disformidade percebida na vista superior resulta na compactação da forma em um ponto de vista específico, onde as elipses se transformam em círculos e o buraco ganha aspecto real. Este curioso efeito é atingido principalmente pelo uso de degrade na criação da profundidade.

O uso de texturas visuais e cores vibrantes têm a capacidade de ressaltar uma figura aos nossos olhos. São métodos gráficos diariamente utilizados em propagandas e material publicitário, por exemplo. O efeito criado (Figura 9) é de volumetria a uma forma bidimensional, alcançado pela curvatura nas linhas centralizadas. Este método ocasionou a quebra da linearidade apresentada pelas retas horizontais, e acabou por delinear o contorno da mão.

A Figura 10 apresenta uma ilusão de óptica que utiliza da imagem de um dragão como elemento figurativo. Seu download é disponibilizado em sites e blogs de curiosidades, sendo sua montagem, indicada a todos os interessados com qualquer nível de habilidades manuais. Utiliza-se da metodologia básica da dobradura em papel para criação da volumetria, bem como a coloração em pontilhismo para alcance de profundidade na textura visual. As dobras denominadas de Vale e de Montanha referem-se ao sentido de flexão do papel, sendo empregadas há muito na confecção dos origamis japoneses. Realizou-se experimentação relativa à luminosidade necessária para pleno funcionamento da sensação ilusória, onde o dragão parece acompanhar pelo olhar e movimentação da cabeça, o deslocamento de seu observador. O resultado foi a premissa de iluminação direta com foco frontal ou posterior ao dragão, com intuito de difusão e uniformidade aos planos para alcance da volumetria.

Com intuito da observação de espaços que comportassem elementos e/ou obras relacionadas ao tema em discussão, foram efetuadas visitas técnicas no Instituto 
Inhotim com registro por meio de anotações e fotografias. Buscou-se compreender não apenas como, mas também o porquê das reações fisiológicas presenciadas e, para natural alcance destas informações, a existência desta pesquisa de campo não foi divulgada aos usuários.

O Bissexted Triangle de Dan Grahan (Figura 11) consiste em uma estrutura triangular com ausência de fechamento superior que utiliza lâminas de vidro semireflexivo como divisórias, sendo as externas superfícies planas e, a interior, curva. Esta curvatura resulta na criação de uma superfície espelhada com efeitos ópticos opostos, vistos um por vez e de acordo com o posicionamento do observador (resultante da escolha entre duas entradas existentes na obra). Tomando sua ponta de menor angulação como o Norte, temos estas entradas posicionadas a Leste e Oeste. Se escolhido o portal a Leste, o observador visualiza sua imagem espelhada de modo côncavo e tem seu reflexo alargado. Já para o portal a Oeste, o efeito é convexo, afinando assim a imagem refletiva. Por se tratar de um material translúcido, a divisória em vidro permite contato visual simultâneo entre os participantes destes efeitos visuais, fazendo desta uma experiência propositalmente coletiva. As reações referentes a esta obra foram de natureza positiva. Os observadores se divertiram com a análise dos formatos corporais distorcidos, fazendo referência à necessidade da realização de exercícios físicos em tons de brincadeira.

A Viewing Machine (Figura 12) é composta por uma estrutura metálica em formato de tubo hexagonal e, em seu interior, a utilização de espelhos para criação dos efeitos de caleidoscópio. Proporcionadas por reflexos criados pela luz solar rebatida nos espelhos, diferentes imagens multiplicadas formam-se em arranjos simétricos. Na etimologia da palavra caleidoscópio, estão as palavras gregas kalos (belo), eidos (forma) e scopos (observador) - "observador de belas formas". O visitante é convidado a manusear esta máquina, apontando-a para o local de seu interesse. 0 curioso efeito desta multiplicação implica na distorção da paisagem, ou forma, presente ao lado contrário onde se encontra o observador, promovendo a direta interação com o entorno. Trata-se de um uso realizado tanto individual quanto coletivamente, o que permite maior liberdade à experimentação dos usuários. As reações presenciadas foram por maioria de surpresa e encantamento pela ilusão, acompanhadas por uma série de fotografias pelos usuários.

\subsection{Figuras}

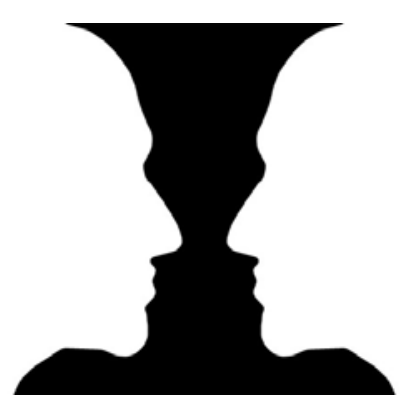

Figura 1 - Exemplo de ilusão ambígua.

Fonte: Acesso em 18/06/2015: <https://www.ideafixa.com/ambiguidade-visual-na-arte> 


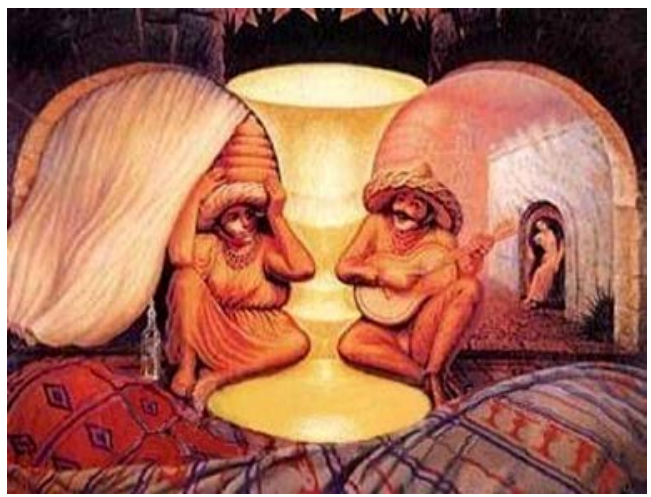

Figura 2 - Exemplo de ilusão escondida.

Fonte: Acesso em 18/06/2015: <http://www.curiosityflux.com/2014/07/ilusao-de-otica.html>

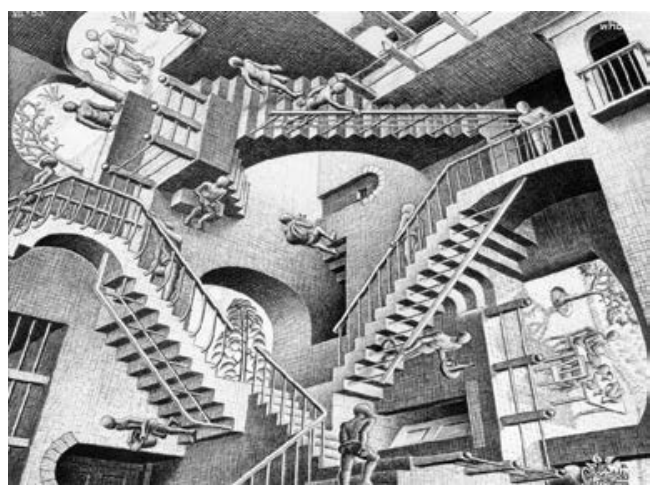

Figura 3 - Exemplo de ilusão paradoxal.

Fonte: Acesso em 18/06/2015:< http://ahduvido.com.br/alguns-paradoxos-classicos-que-afligem-ahumanidade>

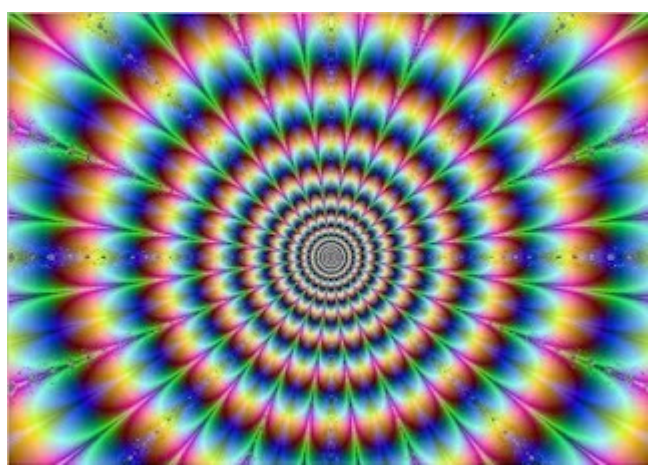

Figura 4 - Exemplo de ilusão anáglifa.

Fonte: Acesso em 18/06/2015:< http://www.curiosityflux.com/2014/07/ilusao-de-otica.html>

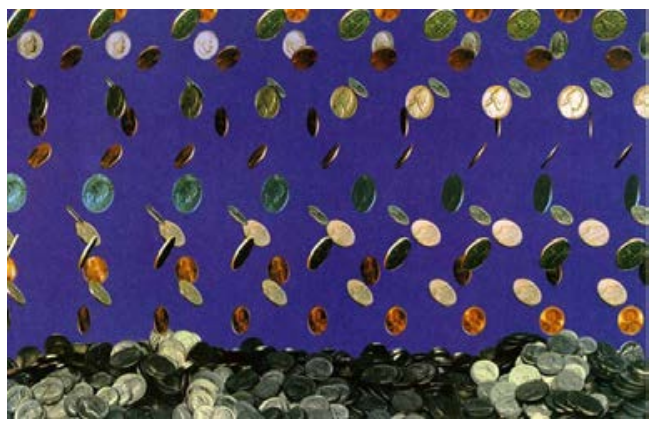

Figura 5 - Exemplo de auto-estereograma.

Fonte: Acesso em 18/06/2015:< http://www.curiosityflux.com/2014/07/ilusao-de-otica.html> 


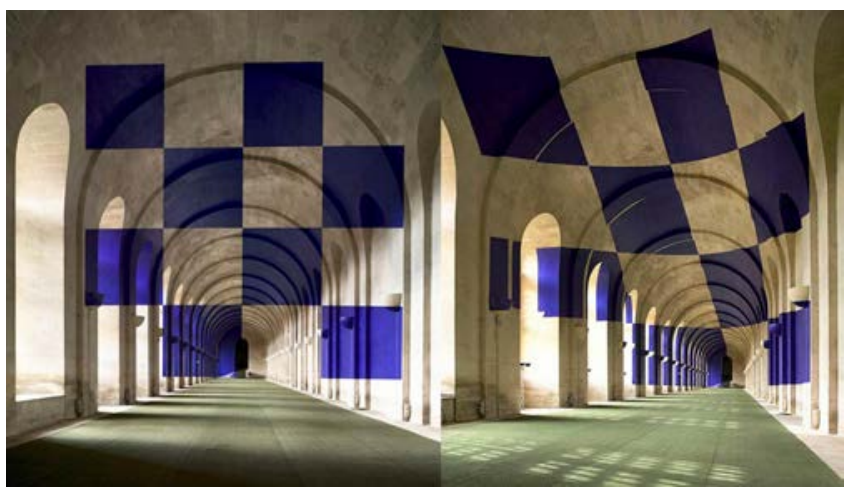

Figura 6 - Exemplo de ilusão anamórfica.

Fonte: Acesso em 18/06/2015:< http://elementoa.blogspot.com.br/2012/05/ilusao-anaformatica-felipevarini.html>

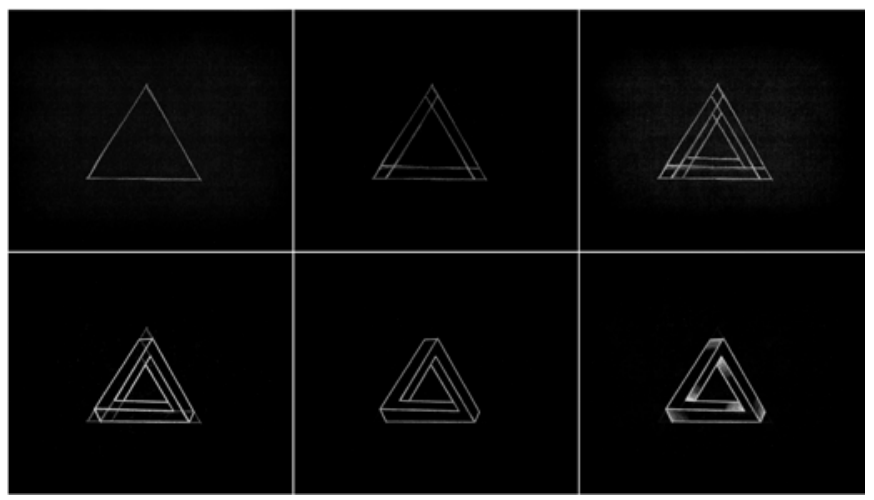

Figura 7 - Processo de estudo manual da ilusão paradoxal, realizado em papel preto com auxílio de lápis pastel branco. Fonte: Elaborada pelo autor, com base na pesquisa realizada.

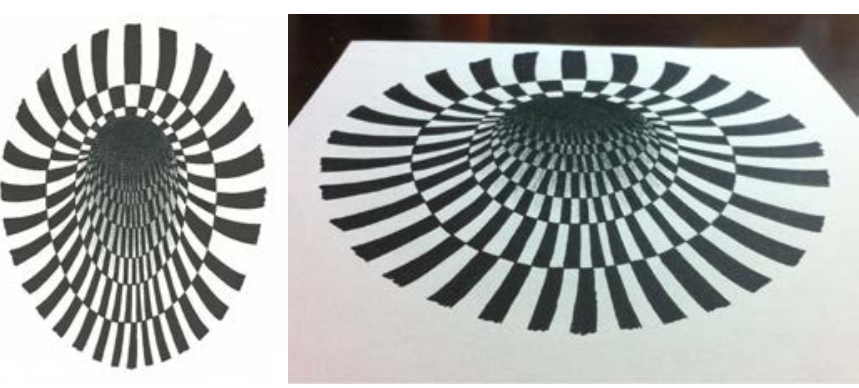

Figura 8 - Estudo manual de perspectiva. À esquerda, vista superior; à direita, ponto de vista específico. Fonte: Elaborada pelo autor, com base na pesquisa realizada.

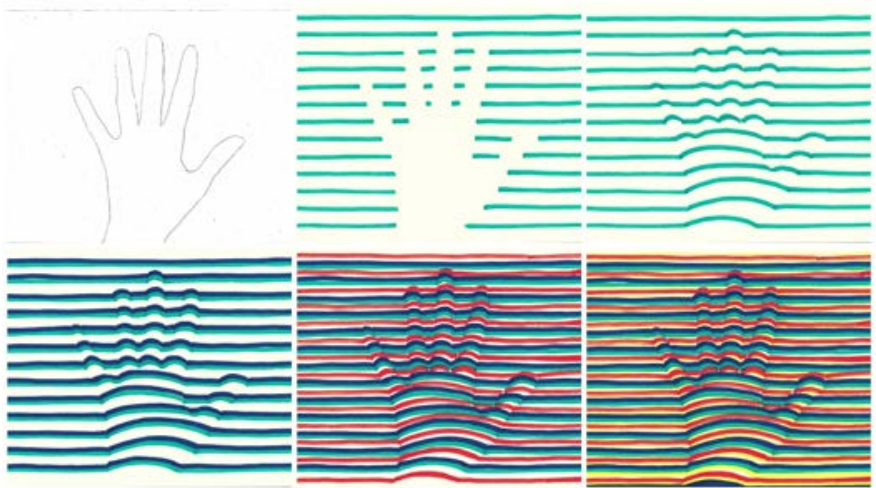

Figura 9 - Processo de estudo manual sobre textura e cor, realizado em papel branco com auxílio de canetas coloridas. Fonte: Elaborada pelo autor, com base na pesquisa realizada. 

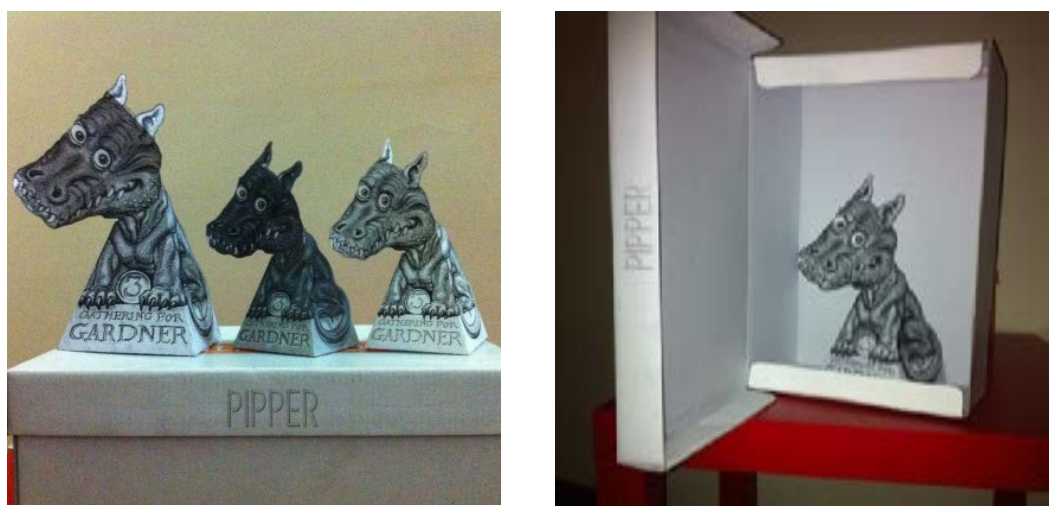

Figura 10 - Estudo manual de ilusão tridimensional.

Fonte: Elaborada pelo autor, com base na pesquisa realizada.
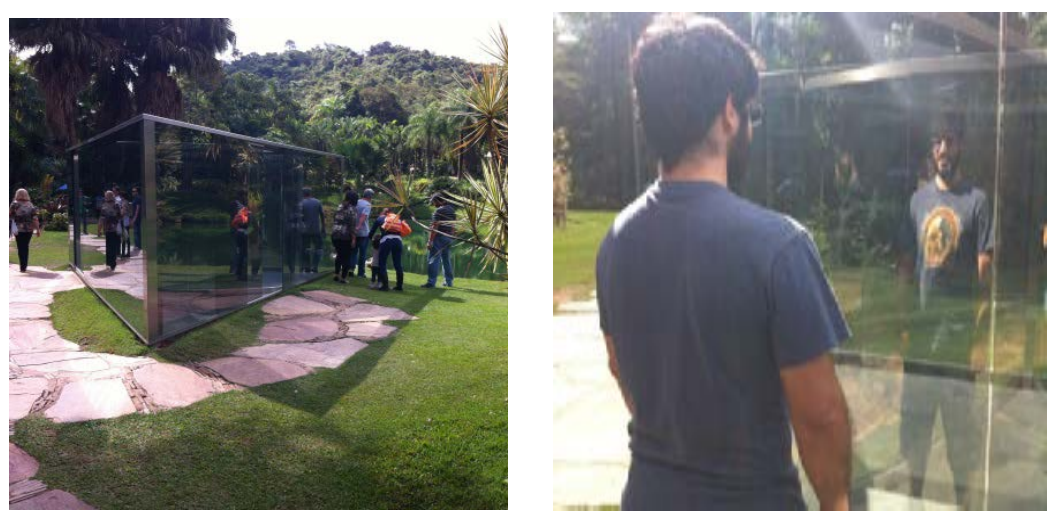

Figura 11 - Obra analisada em visita técnica.

Fonte: Elaborada pelo autor, com base na pesquisa realizada.
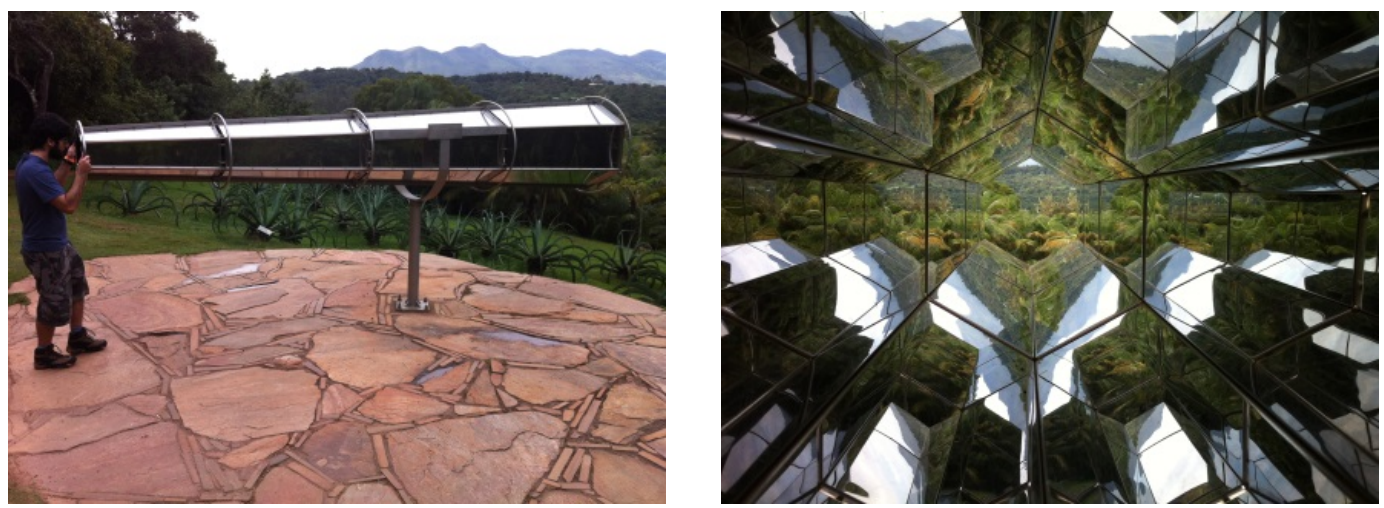

Figura 12 - Obra analisada em visita técnica.

Fonte: Elaborada pelo autor, com base na pesquisa realizada.

\section{CONCLUSÃO}

A ilusão de óptica tende a distorcer conceitos, por vezes, classificados por nós como verdades absolutas, sendo obtida pela aplicação de princípios psicológicos a componentes figurativos, além de apresentar-se como um elemento mutável e flexível. Tem presença constante em nosso processo de visão, visto que, diferentemente do trabalho de mágicos ilusionistas, ela fala por si só permitindo que o observador se sinta atraído pelo efeito ilusório mesmo após seu método ser revelado. 
Tal ponderação, se investida em espaço tridimensional, tem como expectativa elevar a funcionalidade do ambiente ao patamar de encantamento pelo usuário.

Com a valorização financeira do metro quadrado, e consequente busca por moradias reduzidas, é cada vez mais visível o aumento da demanda por espaços primordialmente funcionais. O mesmo se aplica a ambientes públicos e comerciais, onde a valorização do espaço poderia ser melhor explorada com uso do design. Este por sua vez, agrega a interdisciplinaridade como método para obtenção de resultados que visualmente nos parecem ínfimos, porém têm real destaque no campo cognitivo. Tem-se que, incorporados a um ambiente, os atributos constituintes dos efeitos ilusórios atuam atrativa e interativamente, o que valida sua empregabilidade se relacionada à demanda e usabilidade do espaço.

A criação projetual, quando aliada à ilusão de óptica, visa elementos os quais não possam ser ignorados pelos observadores e/ou usuários, tornando-os assim, partícipes da produção. Para tal, intencionam-se efeitos visuais partindo do uso de texturas, formas e cores, em variação às cotidianas. É sabido que para uso tridimensional de ilusões anteriormente comentadas, necessita-se cautela em correspondência aos possíveis, e indesejáveis, efeitos negativos como náuseas e enxaquecas.

Com o desenvolvimento desta pesquisa, pôde-se constatar que dimensionalidades ilusórias se ajustam a diversos tipos de localização e público, porém, este ajuste deve ser previamente intencionado pelo fundador da ilusão ou projeto que abranja o uso de suas metodologias. Além disso, observou-se pelas pesquisas de campo e bibliográfica, que recorrer aos artifícios desta intrigante área da óptica não explicita a essência de um estilo artístico específico e, portanto, pode ser considerada um recurso atemporal.

\section{REFERÊNCIAS}

EAGLEMAN; David. Incógnito: As vidas secretas do cérebro. Rio de Janeiro: Rocco, 2012.

GERRITSEN; Frans. Color: Aparencia óptica médio de expresión artística y fenómeno físico. Barcelona: Blume, 1976.

GOMBRICH; E.H. Arte e ilusão: Um estudo da psicologia da representação pictórica. São Paulo: WMF Martins Fontes, 2007.

HOFFMAN; Donald. Inteligencia visual: Cómo creamos lo que vemos. Barcelona: Paidós, 2000.

LANNERS; Edi. O Livro de Ouro das Ilusões. Editora Tecnoprint, 1982.

MARQUES, Domiciano. Ilusão de óptica. Disponível na internet por http em:< http://www.brasilescola.com/fisica/ilusao-optica.htm >. Acesso em: 13 de mar. 2015.

MARQUES, Domiciano. Óptica. Disponível na internet por http em:< http://www.mundoeducacao.com/fisica/optica.htm >. Acesso em: 12 de mar. 2015.

PINKER; Steven. Como a mente funciona. São Paulo: Companhia das Letras, 2001.

PORTAL DA OFTAMOLOGIA. Ilusões de óptica. Disponível na internet por http em:< http://www.portaldaretina.com.br/ilusoes/ >. Acesso em: 11 de mar. 2015. 
SANT'ANNA, Thais. Como são feitas as ilusões de óptica em perspectiva? Disponível na internet por http em: < http://mundoestranho.abril.com.br/materia/a-fantast >. Acesso em: 19 de mar. 2015.

SCHATTSCHNEIDER, Doris et. al. Caleidociclos de M.C.Escher. China: Evergreen, 2013.

SO BIOLOGIA. Órgão dos sentidos. Disponível na internet por http em: < http://www.sobiologia.com.br/conteudos/Corpo/sentido.php >.Acesso em: 02 de abr. 2015. 